\title{
Parapharyngeal carcinosarcoma treated with an endoscopic-assisted transcervical approach: a case report
}

\author{
Jacopo Matteucci^, Riccardo Lenzi, Luca Muscatello \\ Unit of Otorhinolaringology, Azienda USL Toscana Nord Ovest (ATNO), Apuane Hospital, Massa, Italy \\ Correspondence to: Jacopo Matteucci. Unit of Otorhinolaringology, Azienda USL Toscana Nord Ovest (ATNO), Apuane Hospital, Massa, Italy. \\ Email: matteucci.jacopo81@gmail.com.
}

\begin{abstract}
Background: Primary tumors of the parapharyngeal space (PPS) are very rare, accounting for approximately $0.5-1.5 \%$ of all head and neck tumors. Most of them are benign lesions (80\%) and pleomorphic adenoma is the most common, followed by neurogenic tumors. Multiple surgical approaches have been described, each one offering various functional outcomes, and the transcervical approach still represents the workhorse for head and neck surgeons confronting the PPS. Large tumors, or those located in the upper part of PPS, often require greater mobilization of neural and vascular structures, or combined routes with a mandibulotomy or an infratemporal fossa approach, therefore associated with considerable morbidity.

Case Description: In the present study we report the case of an 81-year-old woman with persistence of a PPS malignant tumor, after radiation treatment. A surgical resection via an endoscopic-assisted transcervical approach was performed. Complete tumour removal was obtained. No intra-, peri- or post-operative complications were reported. Histopathological findings were consistent with salivary carcinosarcoma.

Conclusions: Routinely, PPS tumors are removed through the transcervical approach. Recently, several surgical minimal invasive approaches to PPS have been described, employing endoscopic and robotic assistance via transnasal and transoral windows. The endoscopic-assisted transcervical approach PPS allowed us to remove the tumor in conditions of good visualization, preventing neurovascular injuries and tumor spillage.
\end{abstract}

Keywords: Parapharyngeal space (PPS); endoscopic surgery; salivary glands tumors; transcervical approach; case report

Received: 23 November 2020; Accepted: 16 May 2021; Published: 10 September 2021.

doi: $10.21037 /$ fomm-20-82

View this article at: http://dx.doi.org/10.21037/fomm-20-82

\section{Introduction}

The parapharyngeal space (PPS) is a three-dimensional inverted pyramid-shaped area, extending superiorly from the skull base to the greater cornu of the hyoid bone, inferiorly.

The styloid process, tensor veli palatini muscle and fascia stretching between, separate it in the pre-styloid and post-styloid compartment. The pre-styloid space is mainly occupied by the deep lobe of the parotid gland; the poststyloid compartment contains neurovascular structures within the carotid sheath, as IX, X, XI and XII cranial nerves, the cervical sympathetic chain, the internal jugular vein, and the internal carotid artery. Primary tumours of the PPS are very rare, constituting approximately $0.5-1.5 \%$ of all head and neck tumors (1-4). The majority are benign neoplasm (80\%) and pleomorphic adenoma is the most common, followed by neurogenic tumors $(2,5)$. Patients clinical presentation usually depend on extension of tumour. Contrast-enhanced MRI represents the gold standard radiological imaging. It provides information regarding size, extension and relationship with neurovascular structures. FNAC is the investigation towards the diagnosis which can be undertaken with hystopatological

$\wedge$ ORCID: 0000-0002-3521-2375. 

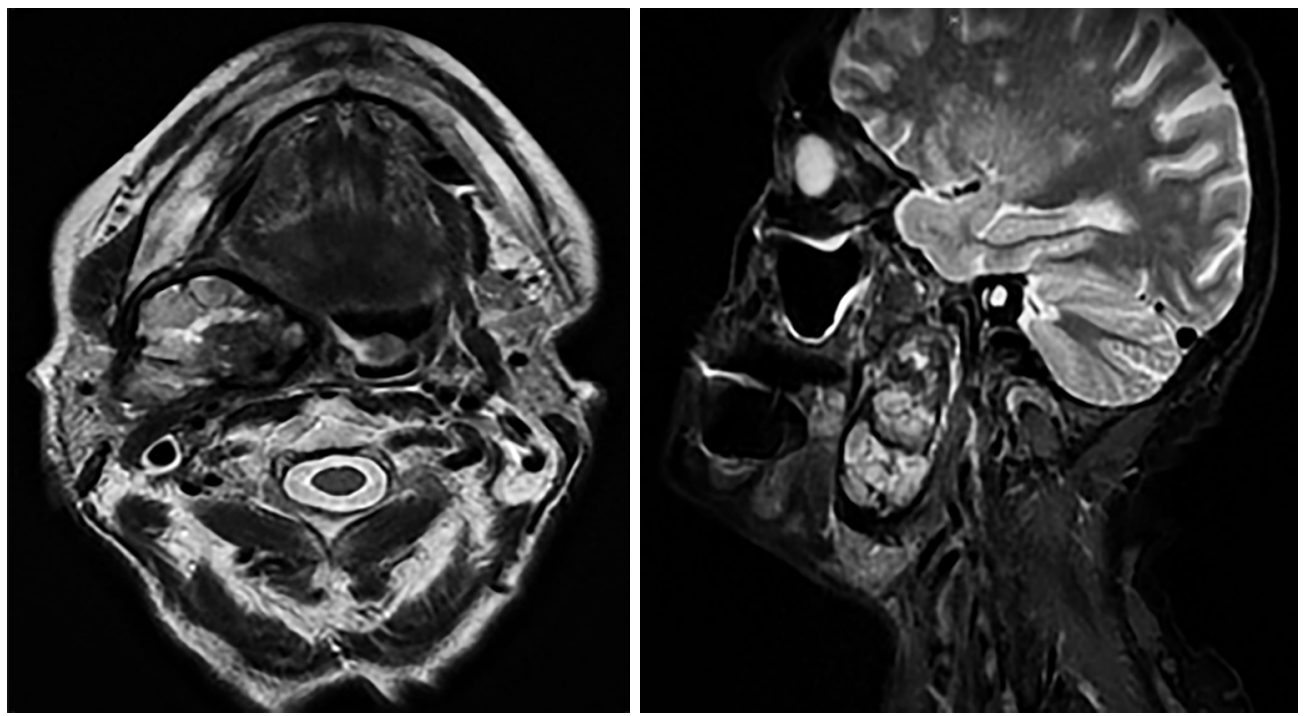

Figure 1 Contrast-enhanced MRI after radiation therapy showed the increasing mass $\left(6 \times 4.5 \times 3.6 \mathrm{~cm}^{3}\right)$, with dishomogeneous contrast enhancement, compressing the lateral pharyngeal wall, without signs of infiltration.

evaluation after surgical treatment.

Routinely, PPS tumors are removed through the transcervical approach. Recently, several surgical minimal invasive approaches to PPS have been described, employing endoscopic and robotic assistance via transnasal and transoral windows (6-9).

In the present study we describe a case of a carcinosarcoma of the deep lobe of the parotid gland resected via an endoscopic-assisted transcervical approach.

\section{Case presentation}

All procedures performed in studies involving human participants were in accordance with the ethical standards of the institutional and/or national research committee(s) and with the Helsinki Declaration (as revised in 2013). Written informed consent was obtained from the patient.

An 81-year-old woman was referred to us for a persistence of right PPS tumor after radiation therapy, performed in another medical center. A PPS mass was found incidentally, and a contrast-enhanced CT scan revealed a dishomogeneous hypointense mass $\left(5.6 \times 4.2 \times 3.2 \mathrm{~cm}^{3}\right)$, extending to the PPS, mimicking a salivary gland abscess, with calcification in the peripheral portion of the sub-mandibular gland. The patient underwent a FNAC that was consistent with angiosarcoma. The medical team treating the patient proposed a surgical approach, but the patient refused. Therefore she was referred to radiotherapy. Her medical history included previous ovarian carcinoma (treated with ovariectomy and adjuvant chemotherapy), and hyperthyroidism. She referred no pain, no skin ulcer and no problems in swelling. At the moment of our examination, a right sub-mandibular mass, fixed to surrounding tissues, was palpable. Contrast-enhanced MRI after radiation therapy showed the increasing mass $\left(6 \times 4.5 \times 3.6 \mathrm{~cm}^{3}\right)$, with dishomogeneous contrast enhancement, compressing the lateral pharyngeal wall, without signs of infiltration (Figure 1). No enlarged cervical nodes were observed. Positive emission tomography (with 18-FDG) revealed a pathological signal in the right PPS (Figure 2). No distant metastases were found.

After a multidisciplinary tumor board discussion, we proposed surgical treatment via an endoscopic-assisted transcervical approach.

\section{Technical notes}

A sub-mandibular skin incision, $8 \mathrm{~cm}$ in its length and 2 to $3 \mathrm{~cm}$ inferior to the lower border of the mandible, was made through the platysma muscle. A sub-platysmal superior flap was elevated. The marginal mandibular branch of the facial nerve was isolated and preserved, monitoring its function during the dissection with the aid of an hand-held nerve stimulator (Neuropacer ${ }^{\circledR}$; FIAB SpA, Florence, Italy). The sub-mandibular was identified and removed, in order to widen the surgical field. Dissection from the anterior border of the sternocleidomastoid muscle and the posterior belly of the digastric muscle was performed. The spinal nerve 


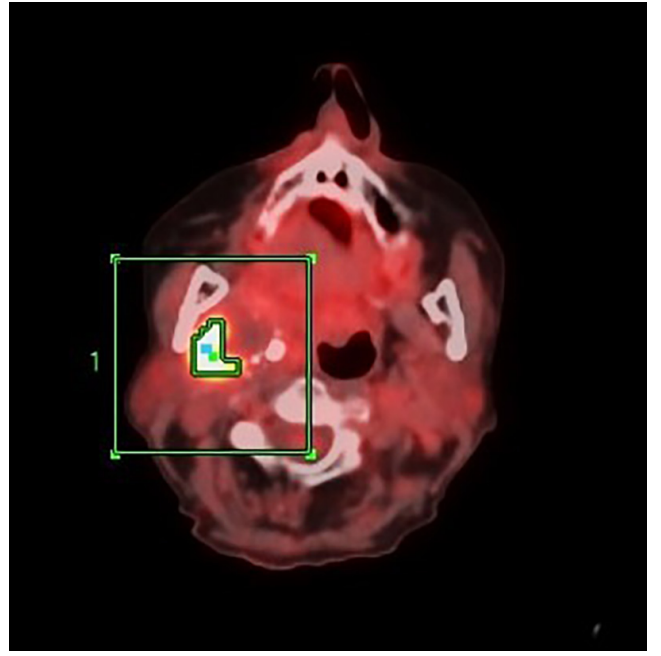

Figure 2 PET (with 18-FDG) revealed a pathological signal in the right PPS. PPS, parapharyngeal space.

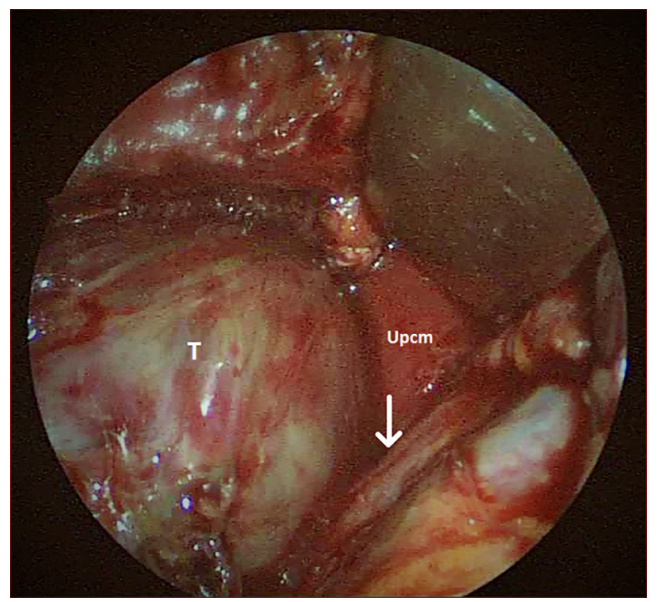

Figure 3 Surgical field: lingual nerve (arrow), adjacent to the mass $(\mathrm{T})$, was isolated and preserved. Upcm, upper pharyngeal constrictor muscle.

was exposed and preserved; the posterior belly of digastric muscle and stylohyoid muscle were identified and divided. The surgical plane was easily dissected under endoscopic view (4 mm, 0 degrees rigid scope; KARL STORZ SE \& Co. KG, Tuttlingen, Germany). Extracapsular separation of the tumor was performed to free the mass from the surrounding tissues. The tumor was completely isolated and removed, using blunt dissection and careful bipolar cautery. A matter of debate is the use of extracapsular dissection for malignant lesions. We didn't perform parotidectomy cause imaging revealed an extraglandular mass. Lingual nerve, adjacent to the mass, was isolated and preserved (Figure 3). Tumor size was $6 \times 5 \times 3 \mathrm{~cm}^{3}$. Surgical procedure lasted three hours .Histopathological findings were consistent with carcinosarcoma of salivary glands, with chondro-sarcomatous and post radiation therapy necrosis components. No intra-, peri- or post-operative neurovascular complications were evaluated and the patient was discharged after three days. Six months later the patient underwent a contrast-enhanced MRI. No loco-regional relapse was found.

\section{Discussion}

Primary tumors of the PPS are very rare, comprising approximately $0.5-1.5 \%$ of all head and neck tumors (1-4). The majority are benign $(80 \%)$, the most common being pleomorphic adenoma of the parotid gland, followed by neurogenic tumors $(5,10-12)$. Salivary gland tumors are predominantly found in the prestyloid compartment, whereas neurogenic tumors typically occupy the poststyloid compartment (2). Dysphagia is the primary complaint of prestyloid tumors; poststyloid tumors are often asymptomatic, but functional impairment in one or more of the cranial nerves may be observed. Contrast-enhanced CT and MRI are the standard radiological investigation for PPS tumors. In our case, we preferred an MRI scan to obtain optimal visualization of the extension of the pathology and tissue infiltration, after cervical radiation treatment.

Carcinosarcoma of the salivary gland is an aggressive malignant tumor, composed of a mixture of carcinomatous and sarcomatous components, that represents less than $0.2 \%$ of all malignant salivary gland tumors (13). Three types of mixed malignant salivary gland tumors can be described: carcinosarcoma ex pleomorphic adenoma, metastasizing pleomorphic adenoma, and carcinosarcoma de novo (14-16). Although most malignant mixed tumors contain a benign and a malignant component, the carcinosarcoma is composed of a mixture of carcinomatous and sarcomatous components. So it can be truly considered a malignant mixed tumor. Other cases have reported cells of chondrosarcoma, fibrosarcoma, leiomyosarcoma, osteosarcoma and malignant fibrous histiocytoma $(17,18)$. Two-thirds of these tumors arise in the parotid gland. They have been described as clinically aggressive, with local recurrence and metastasis observed in up to $50 \%$ of patients. A mean survival range of 29.3 months to 43.2 months has been reported in prior studies $(14,17)$. 
Routinely, PPS tumors are removed through transcervical approaches, which have limited capability to expose the upper portion of the PPS. Thus, blind dissection may curtail risk of tumor rupture, cranial nerve damage and bleeding. Sometimes, combined approaches are required, such as a trans-parotid, trans-mandibular approach with lip incision and mandibular split, that increases morbidity and risk of neurovascular injury. Recently, several minimally invasive surgical approaches to PPS have been described, employing endoscopic and robotic assistance via transnasal and transoral windows. Recently, preauricular approach to PPS is described for treating benign neoplasm, but also controversial in lesions within the parapharyngeal space (19).

Regardless of the surgical technique, potential complications of resecting PPS tumors are various: hemorrhage, cranial nerve injury (VII, IX, X, XI, XII), tumor spillage, Horner Syndrome and stroke (20). Due to its deep position, with complex neurovascular anatomy, the endoscopic-assisted approach has evolved as an acceptable technique for the treatment of PPS tumors, seeking to reduce injury to vital structures, while preserving functioning as well as cosmetic results (21). In our experience, the use of the endoscope improved magnification and allowed dissection of the tumor from adjacent neurovascular structures. No intra- peri- and post-operative complications were recorded.

\section{Conclusions}

The endoscopic-assisted transcervical approach to PPS is an acceptable technique for treating PPS tumors invading the middle and upper PPS, or large tumors requiring more invasive, combined approaches, which may include transmandibular or infratemporal fossa approaches, typically associated with considerable morbidity. High magnification allows good visualization and the possibility of tumor removal, while reducing neurovascular injuries and tumor spillage. Tumor removal is safe, with minimal morbidity and excellent functional outcomes.

\section{Acknowledgments}

Funding: None.

\section{Footnote}

Conflicts of Interest: All authors have completed the ICMJE uniform disclosure form (available at https://fomm. amegroups.com/article/view/10.21037/fomm-20-82/coif). The authors have no conflicts of interest to declare.

Ethical Statement: The authors are accountable for all aspects of the work in ensuring that questions related to the accuracy or integrity of any part of the work are appropriately investigated and resolved. All procedures performed in studies involving human participants were in accordance with the ethical standards of the institutional and/or national research committee(s) and with the Helsinki Declaration (as revised in 2013). Written informed consent was obtained from the patient.

Open Access Statement: This is an Open Access article distributed in accordance with the Creative Commons Attribution-NonCommercial-NoDerivs 4.0 International License (CC BY-NC-ND 4.0), which permits the noncommercial replication and distribution of the article with the strict proviso that no changes or edits are made and the original work is properly cited (including links to both the formal publication through the relevant DOI and the license). See: https://creativecommons.org/licenses/by-nc-nd/4.0/.

\section{References}

1. Bradley PJ, Bradley PT, Olsen K. Update on the management of parapharyngeal tumours. Curr Opin Otolaryngol Head Neck Surg 2011;19:92-8.

2. Carrau RL, Myers EN, Johnson JT. Management of tumors arising in the parapharyngeal space. Laryngoscope 1990;100:583-9.

3. Shahab R, Heliwell T, Jones AS. How we do it: a series of 114 primary pharyngeal spaceneoplasms. Clin Otolaryngol 2005;30:364-7.

4. Stárek I, Mihál V, Novák Z, et al. Pediatric tumors of the parapharyngeal space. Three case reports and a literature review. Int J Pediatr Otorhinolaryngol 2004;68:601-6.

5. Riffat F, Dwivedi RC, Palme C et al. A systematic review of parapharyngeal space tumors reported over 20 years. Oral Oncol 2014;50:421-430.

6. Dallan I, Seccia V, Muscatello L, et al. Transoral endoscopic anatomy of the parapharyngeal space: a stepby-step logical approach with surgical considerations. Head Neck 2011;33:557-61.

7. O'Malley BW Jr, Weinstein GS. Robotic skull base surgery: preclinical investigations to human clinical application. Arch Otolaryngol Head Neck Surg 2007;133:1215-9. 
8. Boyce BJ, Curry JM, Luginbuhl A et al. Transoral robotic approach to parapharyngeal space tumors: Case series and technicall imitations. Laryngoscope 2016;126:1776-82.

9. Benet A, Plata Bello J, El-Sayed I. Combined endonasaltranscervical approach to a metastatic parapharyngeal space papillary thyroid carcinoma. Cureus 2015;7:e285.

10. Batsakis JG, Sneige N. Parapharyngeal and retropharyngeal space diseases. Ann Otol Rhinol Laryngol 1989;98:320-1.

11. Zhi K, Ren W, Zhou H et al. Management of parapharyngeal-space tumors. J Oral Maxillofac Surg 2009;67:1239-44.

12. Olsen KD. Tumors and surgery of the parapharyngeal space. Laryngoscope 1994;104:1-28.

13. Liess BD, Hirschi S, Zitsch RP 3rd, et al. Carcinosarcoma of the parotid gland: report of a case with immunohistochemical findings. Ann Otol Rhinol Laryngol 2007;116:702-4.

14. Gnepp DR. Malignant mixed tumors of the salivary gland: a review. Pathol Annu 1993;28:279-328.

15. Bhalla S, Akhtar N, Prakash P, et al. Carcinosarcoma of Submandibular Salivary Gland with a Rare Sarcomatous

doi: 10.21037/fomm-20-82

Cite this article as: Matteucci J, Lenzi R, Muscatello L. Parapharyngeal carcinosarcoma treated with an endoscopicassisted transcervical approach: a case report. Front Oral Maxillofac Med 2021;3:29.
Variant. Indian J Surg Oncol 2019;10:61-4.

16. Taki NH, Laver N, Quinto T, et al. Carcinosarcoma de novo of the parotid gland: case report. Head Neck 2013;35:E161-3.

17. Stephen J, Batsakis J, Luna MA, et al. True malignant mixed tumors (carcinosarcoma) of salivary glands. Oral Surg Oral Med Oral Pathol 1986;61:597-602.

18. Keh SM, Tait A, Ahsan F. Primary carcinosarcoma of the parotid gland. Clin Pract 2011;1:e117.

19. Valls-Ontañón A, Cuscó-Albors S, Marí-Roig A, et al. Minimally-invasive resection of benign tumours of the parotid gland in the parapharyngeal space. Br J Oral Maxillofac Surg 2019;57:808-9.

20. Duek I, Sviri GE, Billan S, et al. Minimally Invasive Surgery for Resection of Parapharyngeal Space Tumors. J Neurol Surg B Skull Base 2018;79:250-6.

21. Tanjararak K, Upadhyay S, Thiensri T, et al. Potential Surgical Exposure of the Parapharyngeal Internal Carotid Artery by Endonasal, Transoral, and Transcervical Approaches. J Neurol Surg B Skull Base 2018;79:241-9. 